\section{Impaired elimination of metronidazole in decompensated chronic liver disease}

Metronidazole is given to patients with liver disease because of its efficacy against anaerobic organisms. ${ }^{1}$ Although relatively safe, it can cause uncomfortable gastrointestinal and neurological symptoms that may be related to prolonged high blood concentrations of the drug. ${ }^{1}$ Cirrhotic livers have an impaired drug metabolising capacity, ${ }^{2}$ but two recent studies of elimination of metronidazole in liver disease have produced conflicting results. ${ }^{3} 4$ We studied the disappearance of metronidazole from plasma in 10 patients with decompensated chronic liver disease and compared the results with those in nine healthy subjects.

\section{Subjects, methods, and results}

We studied 10 hospital inpatients aged 33-68 with complications of liver disease and with characteristics shown previously to correlate with impaired antipyrine metabolism ${ }^{2}$; alcoholic liver disease had been diagnosed in nine and chronic active hepatitis in one. Nine patients had ascites; three had had episodes of portasystemic encephalopathy (but none at the time of study); serum albumin and bilirubin concentrations were abnormal in all 10; prothrombin time was prolonged (not corrected by vitamin $\mathrm{K}$ ) in seven; and creatinine clearance was reduced in seven. The controls were nine healthy laboratory staff aged 22-38; there is no evidence that clearance of metronidazole varies with age between 20 and 60 years.

Pharmacokinetic data for metronidazole and antipyrine in patients and controls

\begin{tabular}{|c|c|c|c|c|c|}
\hline $\begin{array}{l}\text { Case } \\
\text { No }\end{array}$ & $\underset{\text { (years) }}{\text { Age }}$ & Sex & $\begin{array}{c}\text { Elimination } \\
\text { half life of } \\
\text { metronidazole } \\
\text { (hours) }\end{array}$ & $\begin{array}{l}\text { Clearance of } \\
\text { metronidazole } \\
\text { (ml/min) }\end{array}$ & $\begin{array}{l}\text { Clearance of } \\
\text { antipyrine } \\
(\mathrm{ml} / \mathrm{min})\end{array}$ \\
\hline $\begin{array}{r}1 \\
2 \\
3 \\
4 \\
5 \\
6 \\
7 \\
8 \\
9 \\
10\end{array}$ & $\begin{array}{l}49 \\
50 \\
50 \\
68 \\
49 \\
49 \\
45 \\
33 \\
51 \\
58\end{array}$ & $\begin{array}{l}M \\
M \\
M \\
F \\
F \\
F \\
M \\
F \\
M \\
F \\
M\end{array}$ & $\begin{array}{l}\text { Patient. } \\
17.6 \\
27.3 \\
20.9 \\
16.7 \\
8.6 \\
14.3 \\
23.2 \\
37.6 \\
15.9 \\
16.7\end{array}$ & $\begin{array}{r}23 \cdot 4 \\
13 \cdot 4 \\
14 \cdot 5 \\
20 \cdot 5 \\
28 \cdot 2 \\
16 \cdot 1 \\
9 \cdot 3 \\
3 \cdot 3 \\
20 \cdot 3 \\
25 \cdot 8\end{array}$ & $\begin{array}{c}10.9 \\
7.5 \\
17.8 \\
11.9 \\
12.3 \\
6.9 \\
3.7 \\
4.9 \\
10.5 \\
\text { Not done }\end{array}$ \\
\hline \multicolumn{2}{|c|}{ Mean (SEM) } & & $19.9(2.5)^{*}$ & $17.5(2 \cdot 4) *$ & $9 \cdot 6(1 \cdot 5)+$ \\
\hline \multicolumn{6}{|c|}{ Controls $(n=9)$} \\
\hline
\end{tabular}

${ }^{*} \mathrm{p}<0.001 . \dagger \mathrm{p}<0.0001$ compared with controls.

Metronidazole $8 \mathrm{mg} / \mathrm{kg}$ body weight was administered intravenously over 15 minutes; $2 \mathrm{ml}$ samples of venous blood were drawn before and at $\frac{1}{4}, \frac{1}{2}$, $\frac{3}{3}, 2,4,8,12,23,32$, and 48 hours after infusion. Metronidazole was assayed in serum by high performance liquid chromatography. ${ }^{4}$ Antipyrine clearance was measured seven days after the metronidazole study as described previously, ${ }^{2}$ except that antipyrine was assayed by high performance liquid chromatography. ${ }^{5}$

Elimination half life was calculated by least squares regression analysis of data comprising the terminal portion of a plot of log plasma concentration versus time, and systemic (total body) clearance was calculated as volume of distribution $\times 0.693 /$ elimination half life. Comparisons between groups were assessed using the unpaired Student's $t$ test (two tailed).

Three patients, but no controls, developed side effects including nausea, severe dizziness, ataxia, and burning paraesthesia. Systemic clearance of metronidazole was substantially reduced in the patients compared with the controls (table). Apparent volume of distribution was also somewhat reduced (data not shown), but the greater effect on systemic clearance resulted in a more than twofold prolongation of the elimination half life of metronidazole (table). As a result of this delayed elimination, plasma concentrations greater than twice the usual minimum inhibitory concentration for anaerobes $(6.2 \mu \mathrm{g} /)^{1}$ were present for a mean of $20.0\left(\mathrm{SD}_{1} \cdot 8\right)$ hours in patients compared with $8.3(0.9)$ hours in controls $(p<0.001)$.

Clearance of antipyrine was impaired in all patients (table). There was no correlation between metronidazole and antipyrine clearance or between metronidazole clearance and prothrombin time, serum albumin concentration, serum bilirubin concentration, or creatinine clearance.

\section{Comment}

Elimination of metronidazole was considerably impaired in our patients showing clinical and biochemical evidence of liver failure. Usual dosage regimens would result in prolonged high blood concentrations of metronidazole in such patients and might thus be expected to increase the risk of toxic side effects. Side effects occurred in three of the 10 patients in this study but none of the nine controls.

The present results agree with the data of Ioannides et al, who reported a substantial decrease of systemic clearance of metronidazole in two patients with evidence of liver dysfunction and two others with combined renal and liver impairment. ${ }^{3}$ In another study of six patients with cirrhosis but normal renal function Daneshmand et al found no alteration of elimination of metronidazole. ${ }^{4}$ These different results may reflect either varying degrees of hepatocellular function or a separate role of renal function in eliminating metronidazole.

Clearance of antipyrine was uniformly and profoundly reduced in our patients, supporting an earlier contention that those at greater risk of having impaired drug metabolism can be identified by simple clinical and laboratory findings. ${ }^{2}$ These simple predictors (two or more of ascites, portasystemic encephalopathy, prolonged prothrombin time, and low serum albumin concentration) can now be extended to metronidazole. ${ }^{1}$ Such prediction is only qualitative, however, as no single variable or the rate of clearance of antipyrine correlated linearly with clearance of metronidazole. Clearly, however, the dose and frequency of metronidazole administration should be reduced in patients with decompensated liver disease, especially when renal impairment is present.

This study was supported in part by May and Baker Ltd, Australia, and the National Health and Medical Research Council of Australia.

${ }^{1}$ Goldman P. Metronidazole. N Engl f Med 1980;303:1212-8.

${ }^{2}$ Farrell GC, Cooksley WGE, Hart P, Powell LW. Drug metabolism in liver disease. Identification of patients with impaired hepatic drug metabolism. Gastroenterology 1978;75:580-8.

${ }^{3}$ Ioannides L, Somogyi A, Spicer J, et al. Rectal administration of metronidazole provides therapeutic plasma levels in post-operative patients. N Engl f Med 1981;305:1569-70.

${ }^{4}$ Daneshmand TK, Homeida M, Kaye CM, Elamin AA, Roberts CJC. Disposition of oral metronidazole in hepatic cirrhosis and in hepatosplenic schistosomiasis. Gut $1982 ; 23: 807-13$.

${ }^{5}$ Shargel L, Cheung W-M, Yu ABC. High pressure liquid chromatographic analysis of antipyrine in small plasma samples. F Pharm Sci 1979;68: 1052-4.

(Accepted 14 September 1983)

Department of Medicine, Westmead Centre, Westmead, NSW 2145 , Australia

GEOFFREY FARRELL, MD, FRACP, senior lecturer

LOUIS ZALUZNY, BSC, research assistant

Paediatric Pharmacology Unit, Westmead Centre

JUDITH BAIRD-LAMBERT, PHD, senior scientific officer

MARA CVEJIC, BTC, technical officer

NEIL BUCHANAN, PHD, FRACP, professor of paediatrics

Correspondence to: Dr G Farrell.

\section{Transient retinal ischaemia induced by nifedipine}

Rare ischaemic complications have been reported after oral nifedipine, but none of these affected the retinal circulation. We report on a patient who developed repeated transient unilateral retinal ischaemia after administration of nifedipine.

\section{Case report}

Seven years after suffering an anteroseptal myocardial infarction a 67 year old man presented with angina of one year's duration that did not respond 